\title{
Glucoraphenin, sulfuraphene, and antiproliferative capacity of radish sprouts in germinating and thermal processes
}

by Li, R., Song, D, Vriesekoop, F., Cheng, L.,Yuan, Q. and Liang, $\mathrm{H}$.

Copyright, Publisher and Additional Information: This is the author accepted manuscript. The final published version (version of record) is available online via Springer Please refer to any applicable terms of use of the publisher.

DOI: $10.1007 / \mathrm{s} 00217-016-2764-3$

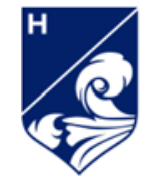

Harper Adams University 


\section{Ruimin Li ${ }^{\|, 1} \cdot$ Dan Song ${ }^{\|, 1,2} \cdot$ Frank Vriesekoop ${ }^{3}$ Li Cheng ${ }^{1}$ Qipeng Yuan ${ }^{1}$ Hao Liang*,1}

${ }^{1}$ State Key laboratory of Chemical Resource Engineering, Beijing University of Chemical Technology,

5

6

7

8

9

10

11

12

13

14

15

16

17

18

19

20

21

22

\section{0} 1
Beijing, P.R. China

${ }^{2}$ Department of Pharmaceutical Engineering, Tianjin vocational college of Bioengineering, Tianjin, P.R. China

${ }^{3}$ Department of Food Science, Harper Adams University, Newport, Shropshire, TF10 8NB, England

"These authors contributed equally to this work.

${ }^{*}$ Corresponding author. Tel.: +86 106443 7610; fax: +86 1064437610 .

E-mail address: lianghao@mail.buct.edu.cn. 
Abstract

2 Glucoraphenin, the predominant glucosinolate in radish sprouts, is hydrolyzed by myrosinase to

3 sulforaphene that is implicated to exert anti-cancerogenic effects. The effects of germination and

4 subsequent cooking processes on the levels of glucoraphenin and its hydrolysis products were

5 investigated in this research. HPLC analysis revealed that the levels of glucoraphenin and sulforaphene

6 decreased with germination time. In agreement with the above results, the antiproliferation activity of

7 radish sprouts extracts on human lung cancer cells was also found to decline gradually in line with the

8 germination process. Furthermore, when we applied three traditional cooking treatments to radish

9 sprouts, the glucoraphenin and sulforaphene were markedly decreased; while the antiproliferation

10 activity of cooked radish sprouts was considerably decreased. This research showed that 3-day-old

11 radish sprouts are an excellent source of bioactive compounds that could potentially benefit human

12 health; while any cooking process appears to cause the devastation of beneficial attributes in radish

13 sprouts.

14 Keywords Radish sprouts $\cdot$ Glucoraphenin $\cdot$ Sulforaphene $\cdot$ Degradation $\cdot$ Antiproliferation. 


\section{Introduction}

A large body of epidemiological studies have indicated that a diet rich in cruciferous vegetables has been associated to a reduction in cancer risk [1-4]. Several studies have revealed that various bioactive functions appear to be related to high amounts of glucosinolates and myrosinase in cruciferous vegetables [5-6]. When plant tissue is mechanically damaged or attacked by pests, glucosinolates and myrosinase are brought into contact, resulting in the glucosinolates being hydrolyzed by myrosinase and they produce a variety of degradation products such as isothiocyanates, thiocyanates, nitriles, epithionitriles and oxazolidine-2-thiones [6-7]. Importantly, the anticancer effects of cruciferous vegetables is thought to arise from isothiocyanates which can increase the activity of phase II enzymes and inhibit the proliferation of cancer cells [8-10].

Sprouts are a popular healthy product in many countries. In recent years, radish sprouts have gained people's attention due to their abundance in bioactive compounds and their perceived health benefits [11-15]. Among bioactive compounds in radish sprouts, sulforaphene (SFE: 4-methylsulfinyl-3-butenyl isothiocyanate), an important isothiocyanate derived from glucoraphenin (GRE: 4-methylsulfinyl-3-butenyl glucosinolate), is strongly associated with anticancer activity [16-17]. In our previous study, we showed that SFE was unstable and easily degraded in the hydrolytic process of GRE and then converted to a cyclic degradation product (MSMTT: 6-[(methylsulfinyl)-methyl]-1, 3-thiazinan-2-thione) [17]. MSMTT was early found and identified by Zhang et al. in radish seed and then they discovered the compound showed no cytotoxicity on human tumor cell lines [18]. Therefore, the degredation process could reduce the bioactivity of SFE (Fig. 1). Moreover, others have reported that the quantity of some bioactive compounds in radish sprouts change during the germination period and that sulfur fertilization could also affect the accumulation of health-promoting phytochemicals in 
radish sprouts $[13,15]$. However, the changes of GRE and its hydrolytic products during the germination process of radish seed have not yet been studied.

3 Cruciferous vegetables and their sprouts are usually subjected to some form of heat treatment to

4 make them suitable for human consumption. However, the choice of cooking method is likely to

5 influence the quantity of glucosinolates and their hydrolysis products. Many of the previous studies

6 investigating the effects of heat treatments on cruciferous vegetables focused on the quantity of

7 glucosinolates in general, but only very few papers studied the change of the quantity of

8 isothiocyanates, which are the actual compounds with biological activity in humans $[18,19]$.

9 Furthermore, effects of cooking have been widely investigated in abundantly available cruciferous

10 vegetables such as broccoli and cabbage [18-22], however there are no studies that investigated the

11 thermal effects on radish sprouts.

12 In the present study we investigated radish sprouts with the aim of examining the changes of levels

of GRE, SFE and MSMTT during the germination process to provide an optimum yield of

14 health-promoting compounds for human consumption. In addition, this study tested how GRE and its

15 hydrolysis products vary following a variety of traditional cooking methods, including boiling,

16 steaming and microwaving. Lastly, in order to determine whether the germination and cooking

17 processes affect the bioactivity of radish sprouts: the antiproliferation activity of aqueous extracts from

18 radish sprouts with different germination times and heat treatments on human non-small cell lung

19 cancer cell lines (H1299 and HCC827) were evaluated.

20 Materials and methods

Materials 
Institute, China Academy of Agriculture Science. The standards (purity $>98 \%$ ) of SFE, GRE and

2 MSMTT were separated and purified from radish seeds in our laboratory and its purity and chemical

3 structure were identified by analytical HPLC, ESI-MS and NMR [17, 23]. Sinigrin (purity $>98 \%$ ) was

4 purchased from Sigma (St. Louis, MO). Methanol and trifluoracetic acid (TFA) used for HPLC were of

HPLC grade and purchased from Fisher Scientific Co., LTD (Tustin, CA). Ultra pure water was obtained by Q Millipore System (Millipore, USA). RPMI-1640 media, fetal bovine serum, penicillin, streptomycin were purchased from Hyclone (Thermo Scientific, USA). $\mathrm{KH}_{2} \mathrm{PO}_{4}, \mathrm{~K}_{2} \mathrm{HPO}_{4}$, DMSO (dimethylsulfoxide) and MTT [3-(4, 5-dimethylthiazol-2-yl)-2, 5-diphenyltetrazolium bromide] were analytical grade and purchased from Beijing Chemical Works (Beijing, China).

The analytical HPLC equipment used in our experiment was a Shimadzu LC-20AT system (Kyoto, Japan) with two LC-20AT solvent delivery units, a SPD-M20A DAD detector, a SIL-20A auto sampler, a CTO-10ASVP column oven, a LC solution workstation and an analytical reverse phase $\mathrm{C}_{18}$ column $(4.6 \times 250 \mathrm{~mm}, 5 \mu \mathrm{m}$; Shimadzu, Japan $)$.

\section{Seeds germination and sprouts cultivation}

One hundred grams of radish seeds were cleaned by rinsing with deionized water then they were immersed in a $0.7 \%$ sodium hypochlorite solution for 30 min. Seeds were drained and washed with deionized water until they reached a neutral $\mathrm{pH}$. Afterwards, seeds were soaked in $500 \mathrm{~mL}$ deionized water overnight. The imbibed seeds were germinated on four layers of moist sterile gauzes in culture trays. The trays were placed in incubators and in order to maintain an even water content the seeds were watered every $8 \mathrm{~h}$. During first two days, seeds were germinated in darkness at $25{ }^{\circ} \mathrm{C}$, after that they were cultivated under photoperiod conditions ( $16 \mathrm{~h} \mathrm{light}$ and $8 \mathrm{~h}$ darkness) at $25{ }^{\circ} \mathrm{C}$. Sprouts were 
were stored at $-20^{\circ} \mathrm{C}$ and the others were freeze-dried.

\section{Quantitation of GRE by HPLC}

The extraction of GRE was conducted according to a previously published method [19, 24], with modifications. Two grams of freeze-dried radish sprouts were ground into powder with an analytical grinder and then added to $20 \mathrm{~mL}$ boiling water. The mixture was heated in a water bath set at $100{ }^{\circ} \mathrm{C}$ for $15 \mathrm{~min}$ before being centrifuged at $10625 \mathrm{~g}$ for $5 \mathrm{~min}$. Subsequently, the supernatant was decanted, and the residue was extracted twice with $20 \mathrm{~mL}$ of boiling water. Then the combined supernatants were concentrated to $20 \mathrm{~mL}$ under vacuum. The extracted concentrate was filtered with $0.22 \mu \mathrm{m}$ nylon membrane and GRE in it was separated using the HPLC system described above with $1 \mathrm{~mL} / \mathrm{min}$ flow rate at $30{ }^{\circ} \mathrm{C}$ by eluting with a isocratic elution of methanol (mobile phase A) and $0.02 \%(v / v)$ TFA aqueous solution (mobile phase B) as follows: isocratically 5\% A kept for $10 \mathrm{~min}, 100 \% \mathrm{~A}$ for $2 \mathrm{~min}$, then $5 \%$ A for $8 \mathrm{~min}$. The injection volume was $20 \mu \mathrm{L}$ per sample and the detection wavelength was set at $235 \mathrm{~nm}$. The concentration of GRE was expressed as $\mu \mathrm{mol} / \mathrm{g}$ dry weight (DW).

\section{Analysis of the formation of SFE and MSMTT by HPLC}

Ten grams of treated or untreated sprouts and $20 \mathrm{~mL}$ deionized water were juiced for $3 \mathrm{~min}$ using a juice centrifuge (Joyoung model JYL-C18D, China). The obtained slurry was allowed to hydrolyze in situ at room temperature for $20 \mathrm{~min}$ to facilitate product formation. Following hydrolysis the slurry was centrifuged at $10625 \mathrm{~g}$ for $5 \mathrm{~min}$ and filtered with $0.22 \mu \mathrm{m}$ nylon membrane. SFE and MSMTT formed in the slurry were separated by HPLC with $1 \mathrm{~mL} / \mathrm{min}$ flow rate at $30^{\circ} \mathrm{C}$ by eluting with a gradient elution of methanol (mobile phase A) and 0.02\% (v/v) TFA aqueous solution (mobile phase B) as follows: linear gradient from 5\% A to $80 \%$ A for 30 min, 100\% A kept for 2 min, then 5\% A kept for 8 min. The injection volume was $20 \mu \mathrm{L}$ and the detection wavelength was set at 254 and $281 \mathrm{~nm}$ for SFE 
and MSMTT respectively [17]. The formation of SFE and MSMTT were expressed as $\mu \mathrm{mol} / \mathrm{g}$ dry

2 weight (DW).

\section{Cooking treatments}

Radish sprouts germinated for three days were collected and processed within $24 \mathrm{~h}$. A control and three cooking treatments including boiling, steaming and microwaving were conducted in this experiment. Different cooking times were executed aimed to evaluate the influence of different durations of cooking on the levels of GRE, SFE and MSMTT and the potential anticancer activity of radish sprouts. For steam treatment, ten grams of radish sprouts were steamed using an electric steamer (Supor model Z09YA4-G2, China) for 0.5, 1, 1.5, 2, 3, 5 min. For boiling, ten grams of radish sprouts were placed into a pot of boiling water around $500 \mathrm{~g}$ for $0.5,1,1.5,2,3,5 \mathrm{~min}$ to conduct boiling treatment. Microwaving was conducted in a microwave oven (Galanz model MC-83105FB, China) at $800 \mathrm{~W}$. Ten grams of radish sprouts were put in a heat-resistant dish containing ten grams of water and then microwave heating for $0.5,1,1.5,2 \mathrm{~min}$ [21-22]. Samples of germinating radish sprouts were withdrawn at appropriate times and the thermal treatment halted by immediate immersion in iced-water. Subsequently, one half of the sprouts were subjected to analysis of SFE and MSMTT by HPLC and the others was freeze-dried then analyzed GRE as described above.

The extraction of myrosinase was conducted according to previously published method [25], with modifications. Ten grams of raw or heat treated radish sprouts (boiling, steaming or microwaving for $0.5 \mathrm{~min}$ ) were homogenized with $20 \mathrm{~mL}$ buffer (sodium phosphate $10 \mathrm{M}, \mathrm{pH} 7.0$, containing ethylene diamine tetraacetic acid $1 \mathrm{mM}$, dithiothreitol $3 \mathrm{mM}$, and $5 \%$ glycerol) for $3 \mathrm{~min}$ in an ice bath and centrifuged at $10625 \mathrm{~g}$ for $5 \mathrm{~min}$ at $4{ }^{\circ} \mathrm{C}$. The supernatants were collected and ammonium sulfate was added until the final concentration of ammonium sulfate reached saturation ( $255 \%)$. The mixture was 
1 kept at $4{ }^{\circ} \mathrm{C}$ for $2 \mathrm{~h}$ to precipitate the protein fraction. This was then centrifuged at $10625 \mathrm{~g}$ for $15 \mathrm{~min}$

2 at $4{ }^{\circ} \mathrm{C}$. The pellet was dissolved in $2 \mathrm{~mL}$ buffer (sodium phosphate 10M, pH 7.0) and dailysed against

3 the same buffer at $4{ }^{\circ} \mathrm{C}$ for $24 \mathrm{~h}$. Then the mixture was used as a crude myrosinase preparation.

4 Myrosinase activity was determined by evaluating the rate of hydrolysis of sinigrin. Briefly, $200 \mu \mathrm{L}$ of myrosinase and $10 \mu \mathrm{L}$ sinigrin $(2 \mathrm{mg} / \mathrm{mL})$ were reacted at $37{ }^{\circ} \mathrm{C}$ for $15 \mathrm{~min}$, then it was boiled for 5 min to stop the reaction. The residual sinigrin in the reaction system was measured by HPLC with 1 $\mathrm{mL} / \mathrm{min}$ flow rate at $30^{\circ} \mathrm{C}$ by eluting with a gradient elution of methanol (mobile phase A) and $0.02 \%$ (v/v) TFA aqueous solution (mobile phase B) as follows: linear gradient from $1 \%$ A to $70 \%$ A for 20 $\min , 100 \%$ A kept for $2 \mathrm{~min}$, then $1 \%$ A kept for $8 \mathrm{~min}$. The injection volume was $20 \mu \mathrm{L}$ and the detection wavelength was set at $235 \mathrm{~nm}$. The protein content of the myrosinase preparation was determined by the commassie brilliant blue method (REF) [26]. Myrosinase activity was expressed as units per milligram of protein.

\section{Non-small cell lung cancer culture}

Human non-small cell lung cancer H1299 cells and HCC827 cells obtained from the American Type

Culture Collection (Manassas, VA), were cultured in RPMI-1640 media supplemented with 10\% fetal bovine serum, 100 units $/ \mathrm{mL}$ penicillin, and $100 \mu \mathrm{g} / \mathrm{mL}$ streptomycin. Cultured cells maintained at 37 ${ }^{\circ} \mathrm{C}$ in a humidified $5 \% \mathrm{CO}_{2}$ atmosphere.

Preparation of radish sprouts extracts for cell experiment

Approximately ten grams of raw and heat treated radish sprouts were juiced with $20 \mathrm{~mL}$ deionized water for 3 min using a commercial juice centrifuge (Joyoung model JYL-C18D, China). The obtained slurry was allowed to hydrolyze in situ at room temperature for $20 \mathrm{~min}$ to facilitate product formation. 
1 which the supernatants were freeze-dried [27].

\section{Antiproliferative effects}

The antiproliferative effects of radish sprouts extracts was evaluated by tetrazolium reduction assay, based on the reduction of metabolically active cells. Briefly, 5000 cells/100 $\mu \mathrm{L}$ were seeded into each well of 96-well plates and cultured for $12 \mathrm{~h}$. Then cells were treated with $100 \mu \mathrm{L}$ of media containing $10 \mu \mathrm{g}$ raw or heat treated radish sprouts extracts. Five replicate wells received each treatment, and they were cultivated for 24,48 and $72 \mathrm{~h}$. Afterwards, $20 \mu \mathrm{L}$ of MTT at a concentrate $5 \mathrm{mg} / \mathrm{mL}$ in PBS was added to each well and the cells were cultured at $37{ }^{\circ} \mathrm{C}$ for $4 \mathrm{~h}$. Treatment media was removed and then $150 \mu \mathrm{L}$ of DMSO was added, and then the absorbance of each well was measured in a model 680 microplate reader (BIO-RAD, USA) at $490 \mathrm{~nm}$ [27-29]. The results were expressed as percentage of the controls.

Statistical analysis

All experiments were carried out in three independent replicates and data were expressed as mean \pm standard deviation $(n=3)$. Origin 7.5 (OriginLab, USA) was used to prepare figures. SPSS 18.0 (SPSS Inc., Chicago, IL) were used to analyse significant difference followed by Duncan's multiple range tests $(\mathrm{P}<0.05)$.

\section{Results and discussion}

\section{Effects of germination on the quantity of GRE in radish sprouts.}

Like other cruciferous plants, radish sprouts contain several different glucosinolates. However, GRE is the predominant glucosinolate in raw radish seeds and sprouts [13-15]. Fig. 2 shows the influence of germination time on the quantity of GRE in radish sprouts. The concentration of GRE was depleted during germination, it decreased by $80.2 \%$ after 7 days germination under our conditions. Similarly, 
1 Zhou et al. reported a reduction of $89.2 \%$ in the GRE when radish sprouts were cultivated for 7 days

2 [15]. This decrease of the GRE in germination process was from tissue expansion and the growth of

3 sprouts [30].

4 Effects of germination on the formation of SFE and MSMTT in radish sprouts.

5 SFE is produced from GRE by myrosinase when radish sprouts are damaged or otherwise attacked

6 by herbivores. In our previous study, we found that SFE was unstable and readily degraded in the

7 hydrolytic process of GRE and then converted to a cyclic degradation product (MSMTT) [17], which

8 could reduce the bioactivity of SFE (Fig. 1). In our current study, along with the depletion of the GRE

9 content, SFE formation decreased (Fig. 1 and Fig. 2) in a time-dependent manner during germination

process. A high level of SFE $(96.9 \mu \mathrm{mol} / \mathrm{g} \mathrm{DW})$ was detected in radish seeds. After 3 days of

11 germination, it decreased to $85.2 \mu \mathrm{mol} / \mathrm{g} \mathrm{DW}$, and then followed by a further decrease from 3 to 7 days, reaching $13.5 \mu \mathrm{mol} / \mathrm{g} \mathrm{DW}$ at 7 days. However, the formation of MSMTT increased and reached its highest value $(4.5 \mu \mathrm{mol} / \mathrm{g} \mathrm{DW})$ at 5 days and then stayed at this level (Fig. 2). It is well known that

14 SFE mainly evolve from the hydrolysis of GRE facilitated by myrosinase [31]. Our results suggest that the activities or contents of myrosinase in radish sprouts increase at 3 days into the germination process,

16 and with a marked decrease in SFE levels after 3 days of germination. Therfore, based on the results,

17 3-day-old radish sprouts appear to represent the most optimized condition for the synthesis of 18 functional compounds.

19 Antiproliferative effects of aqueous extracts from raw radish sprouts on human non-small cell

\section{lung cancer.}

21 In the present study, the antiproliferative effects of aqueous extracts from radish sprouts germinated for different times were evaluated on human non-small cell lung cancer H1299 cells and HCC817 cells. 
1 When cells were treated with $0.1 \mathrm{mg}$ of radish sprouts extracts $/ \mathrm{mL}$ of media, the maximum concentration of SFE received by cells was $35.2 \mu \mathrm{M}$ from the extracts of radish seeds (cultivated 0 day) and the minimum was $5.3 \mu \mathrm{M}$ from the extracts of 7-day-old sprouts. Fig. 3 shows the antiproliferative effects on two lung cancer cell cultures (H1299 and HCC299) exposed to extracts from radish sprouts. Radish sprouts germinated less than 3 days could significantly $(p<0.05)$ inhibit the proliferation of the cells. However, 7-day-old sprouts had a negligible inhibitory influence $(\mathrm{P}>0.05)$ compared to the control. The decrease of SFE formation in the germination process of radish sprouts contributed much to these results. These findings indicate that germination time of radish sprouts could be an important impact on their antiproliferative activity with regards to lung cancer cell cultures. Our results are in contrast with those of Martínez-Villaluenga who reported no noticeable toxic effects of fresh radish sprouts on the proliferation and viability of the human promyelocytic leukemia cells: HL-60 [32]. The differences in our observations may be due to the differences in species of radish sprouts and/or cell lines used. Especially, the drug sensitivity of different cell lines can be distinctively different [33].

In this work, 3-day-old radish sprouts had noticeable antiproliferative effects on human lung cancer H1299 and HCC817 cells. When cells treated with $0.1 \mathrm{mg}$ of 3-day-old sprouts extracts/mL of growth medium, the concentration of SFE was $20.4 \mu \mathrm{M}$. We compared these crude extracts with 20.4 $\mu \mathrm{M}$ of purified SFE with regards to their antiproliferative effects. Interestingly, Fig. 4 shows that the extracts provide some advantage $(\mathrm{P}<0.05)$ compared to purified SFE on HCC817 cells. This result could be due to the other isothiocyanates in radish sprouts which had antiproliferative effects as well.

\section{Cooking treatments}

Radish sprouts are usually subjected to some form of heat treatment to make them more suitable for human consumption. However, any cooking process could influence the glucosinolate-myrosinase 
1 system in radish sprouts. Thus, we also investigated the effects of various cooking processes on the level of GRE and its hydrolysis products in radish sprouts. GRE and its hydrolysis products were

3 affected by cooking treatments and cooking time (Fig. 5). Earlier work had indicated that the

4 glucosinolate-myrosinase system was modified during the heating process of cruciferous vegetables due to partial or total inactivation of myrosinase or leaching of glucosinolates [21]. In order to evaluate the influence of a variety of household-like thermal treatments on the levels of GRE, SFE in radish sprouts, we used boiling, steaming and microwave treatments. As shown in Fig. 5A, boiling significantly $(\mathrm{P}<0.05)$ depleted the GRE content and SFE formation. Our analysis shows that the content of GRE was decreased to $21.1 \%$ and $15.1 \%$ after boiling sprouts for 3 and 5 min respectively. Boiling is a conventional way of cooking with a relatively large amount of water involved in the preparation of vegetables where a substantial surface area of vegetables is contacted with boiling water. We measured GRE in the cooking water and found that $75.8 \%$ and $80.4 \%$ of the total GRE was leached into cooking water after sprouts were boiled for 3 and 5 min. Therefore, leaching of GRE into the cooking water can be considered to be the main route by which GRE is lost from sprout tissue [34]. Furthermore, the level of SFE experienced an even greater loss during boiling. Even boiling for $0.5 \mathrm{~min}$ prior to hydrolysis resulted in a loss of SFE production of $97.2 \%$; while MSMTT gradually decreased during the boiling process. loss compared with raw sprouts (Fig. 5B). However, the formation of SFE dropped markedly after steaming even for a short time, however more SFE was retained compared to boiling even after extended steaming. 
declined dramatically when microwaving continued beyond $1 \mathrm{~min}$. Microwaving for 1.5 or $2 \mathrm{~min}$ contributed to almost complete loss of GRE and its hydrolysis products (Fig. 5C). Thus, microwave heating for more than $1 \mathrm{~min}$ is undesirable due to the serious loss of the predominate glucosinolate. However, even if a short microwaving time $(0.5 \mathrm{~min})$ was utilized, sprouts showed significantly $(\mathrm{P}<0.05)$ decreased of SFE formation compared to control sample.

Myrosinase activity was significantly decreased $(\mathrm{P}<0.05)$ even after a short $(0.5 \mathrm{~min})$ cooking treatment, including boiling, steaming and microwaving (Table 1). The myrosinase activity in raw radish sprouts was $1.81 \pm 0.006 \mathrm{U} / \mathrm{mg}$, which decreased by $95 \%$ and $95.6 \%$ after microwaving and boiling for $0.5 \mathrm{~min}$ respectively. Steaming provided the highest retention of myrosinase activity, however, it still caused a marked decrease of $88.4 \%$ after $0.5 \mathrm{~min}$. These data suggest that myrosinase in radish sprouts is heat sensitive, and is readily inactivated during any cooking process and duration.

Effects of cooking have been widely investigated in broccoli. Early work has reported that microwaving and boiling could decrease the content of glucosinolates in broccoli. Steaming, on the other hand, appeared to minimize the loss of glucosinolates [19]. Our present study is in agreement with previous results. Furthermore, it has been known that short steaming periods yield less nitrile and more sulforaphane yield from broccoli [20]. Unlike broccoli, radish has been shown to contain no ESP and therefore heating to destroy ESP does not switch formation of nitrile to formation of isothiocyanate, providing no improvement in isothiocyanate formation from low heat [35-36]. This study demonstrated that all cooking methods significantly $(\mathrm{P}<0.05)$ diminished SFE formation. Even following a brief heating period, sprouts were no longer able to yield large amounts of SFE. We found that the leaching of GRE and denaturing myrosinases during cooking treatments are the main factors that contributed the significant loss of SFE. Our results can be generalized to suggest that the consumption of raw radish 
sprouts will provide the greatest SFE availability.

MSMTT is reported to be generated due to the presence and availability of the hydrogen sulfide in cruciferous vegetables [17, 37-38]. From Fig. 5, we found that the content of MSMTT decreased after three cooking treatments. We inferred that heating could drive away the hydrogen sulfide in the radish sprouts and slightly inhibit the degradation of SFE.

Antiproliferative effects of aqueous extracts from heat treated radish sprouts on human non-small cell lung cancer.

As stated previously, all cooking methods depleted the SFE formation. In order to determine whether the cooking treatment could influence the anticancer activity in spite of a marked drop in SFE, as such we evaluated the effects of short time cooking on the antiproliferative activity of radish sprouts on human non-small lung cancer H1299 and HCC827 cells. Three-day-old radish sprouts were exposed to a a brief heat treatment (boiled or steamed or microwaved for $0.5 \mathrm{~min}$ ) and then prepared their aqueous extracts. The addition of freeze-dried aqueous extracts from any of the cooking methods did not impose strong antiproliferative activity of radish sprouts on human lung cancer H1299 and HCC827 cells compared to a control culture with no additions (Fig. 6). Contrary, the raw sprouts showed obvious inhibitory effects $(\mathrm{P}<0.05)$. Our results indicate that radish sprouts essentially lose their antiproliferative activity on lung cancer cells even after a very short cooking time. Moreover, the decrease of SFE formation during the cooking processes contributed much to these results.

\section{Conclusions}

20 The effects of germination and cooking processes on levels of GRE, SFE and MSMTT in radish sprouts were studied in this research. Our findings suggest that 3-day-old radish sprouts are an excellent source of GRE and SFE which could potentially benefit human health. However, even modest 
1 cooking processes could deplete the GRE content and SFE formation, resulting the loss of the

2 antiproliferative activity of radish sprouts. Thus eating radish sprouts in raw may be desirable from

3 health perspective.

4 Acknowledgments

5 This study was supported by the Natural Science Foundation of China (Grant No.20806005,

6 21176018) and the National High Technology Research and Development Program of China (863

7 Program, Grant No. 2012AA021403).

8 


\section{References}

2

1. Ambrosone CB, McCann SE, Freudenheim JL, Marshall JR, Zhang Y, Shields PG (2004) J Nutr 134:1134-1138

2. Joseph MA, Moysich KB, Freudenheim JL, Shiedlds PG, Bowman ED, Zhang Y, Marshall JR, Ambrosone CB (2004) Nut Cancer 50:206-213

3. Neuhouser ML, Patterson RE, Thornquist MD, Omenn GS, King IB, Goodman GE (2003) Cancer EpidemBiomar 12:350-358

4. Voorips LE, Goldbohm RA, Verhoeven DT, van Poppel GA, Sturmans F, Hermus RJ, van den Brandt PA (2000) Cancer Causes Control 11(2):1010-1015

5. Nastruzzi C, Cortest R, Esposito E, Menegatti E, Leoni O, Iori L, Palmieri S (1996) J Agric Food Chem 44:1014-1021

6. Vaughn SF, Berhow MA (2005) Ind Crops Prod 21:193-202

7. Fenwick GR, Heaney RK (1983) Food Chem 11 (4):249-271

8. Liang H, Lai BT, Yuan QP (2008) J Nat Prod 71:1911-1914

9. Zhang YS (2004) Res-Fund Mol M 555:173-190

10. Zhang YS, Tang L (2004) Acta Pharmacol Sin 28 (9):1343-1354

11. Ciska E, Honke J, Kozlowska H (2008) J Agric Food Chem 56:9087-9093

12. Kim HJ, Chen F, Choi JH (2006) J Agric Food Chem 54:7263-7269

13. Martinez-Villaluenga C, Penas E, Ciska E, Piskula MK, Kozlowska H, Vidal-Valverde C, Frias J (2010) Food Chem 120:710-716

14. Yuan GF, Wang XP, Guo RF, Wang QM (2010) Food Chem 121:1014-1019

15. Zhou CG, Zhu Y, Luo YB (2013) J Agric Food Chem 61:7552-7559 
16. Papi A, Orlandi M, Bartolini G, Barillari J, Iori R (2008) J Agric Food Chem 56:875-883

17. Song D, Liang H, Kuang PQ, Tang P, Hu GF, Yuan QP (2013) J Agric Food Chem

61:5097-5102

18. Zhang X, Liu HB, Jia JJ, Lv WH (2010) J Asian Nat Prod Res 2010:113-118

19. Jones RB, Frisina CL, Winkler S, Imsic M, Tomkins RB (2012) Food Chem 123: 237-242

20. Wang GC, Farnham M, Jeffery EH (2012) J Agric Food Chem 60:6743-6748

21. Rungapamestry V, Duncan A, Fuller Z, Ratcliffe B (2006) J Agric Food Chem 54:7628-7634

22. Verkerk R, Dekker M (2004) J Agric Food Chem 52:7318-7323

23. Kuang PQ, Song D, Lv XH, Zhao D, Liang H, Yuan QP (2013) Food Chem 136:309-315

24. Clarke JD, Hsu A, Riedl K, Bella D, Schwartz SJ, Stevens JF, Ho E (2011) Pharmacol Res 64:456-463

25. Li X, Kushad MM (2005) Plant Physiol Bioch 43:503-511

26. Bradford MM (1976) Anal biochemistry 72:248-254

27. Hanlon PR, Webber DM, Barnes DM (2007) J Agric Food Chem 55:6439-6446

28. Frias J, Gulewicz P, Villaluenga CM, Penas E, Piskula MK, Kozlowska H, Ciska E, Gulewicz K, Valverde CV (2010) J Agric Food Chem 58:2331-2336

29. Frias J, Gulewicz P, Villaluenga CM, Pilarski R, Blazquez E, Jimenez B, Gulewicz K, Valverde CV (2009) J Agric Food Chem 57:1319-1325

30. Perez-Bzlibrea S, Moreno DA, Garcia-Viguera C (2010) J Food Sci 75:C673-C677

31. Liang H, Li C, Yuan Q, Vriesekoop F (2007) J Agric Food Chem 55(20):8047-8053

32. Martínez-Villaluenga C, Frías J, Gulewicz P, Gulewicz K, Vidal-Valerde C (2008) Food

chem toxicol 46:1635-1644 
33. Zhang YS, Tang L, Gonzalez V (2003) Mol Cancer Ther 2:1045-1052

34. Vallejo F, Tomás-Barberán FA, García-Viguera C (2002) Eur Food Res Technol 215(4):

3 $310-316$

4 35. Cole RA (1980) J Agric Food Chem 31:549-557 36. Petroski RJ, Tookey HL (1982) Phytochemistry 21:1903-1905 37. Chin HW, Lindsay RC (1993) J Food Sci 58:835-839

7 38. Kanda K, Tsuruta H (1995) Soil Sci Plant Nutr 41:321-328

8 
Figure captions:

2 Fig. 1 The formation and degradation of sulforaphene (SFE) and chromatograms of the analysis

3 HPLC of SFE in radish sprouts germinated for $0,3,7$ days

Fig. 2 Levels of glucoraphenin (GRE), sulforaphene (SFE) and its hydrolysis product (MSMTT) in radish sprouts germinated for 0-7 days. The data were expressed as mean \pm standard deviation $(n=3)$. Means with different letters reflect the significant difference in the levels of GRE, SFE and MSMTT respectively $(\mathrm{P}<0.05)$

Fig. 3 Effects of aqueous extracts from radish sprouts on the proliferation of human lung cancer H1299 (A) and HCC817 cells (B). The cells were treated with the aqueous extracts from radish sprouts germinated for 0-7 days. The data were expressed as mean \pm standard deviation $(n=3)$. Means with different letters at each time point differed significantly $(\mathrm{P}<0.05)$

Fig. 4 The proliferation curves of human lung cancer H1299 (A) and HCC817 cells (B) exposed to the aqueous extracts from 3-day-old radish sprouts or $20 \mu \mathrm{M}$ sulforaphene (SFE). The data were expressed as mean \pm standard deviation $(\mathrm{n}=3)$. Means with different letters at each time point differed significantly $(\mathrm{P}<0.05)$

Fig. 5 Effects of three heat treatment methods on the levels of glucoraphenin (GRE), sulforaphene (SFE) and its hydrolysis product (MSMTT) in radish sprouts. Three-day-old radish sprouts radish sprouts were heated by boiling (A), steaming (B) and microwaving (C) for various time periods. The data were expressed as mean \pm standard deviation $(n=3)$. Means with different letters reflect the significant difference in the levels of GRE, SFE and MSMTT respectively $(\mathrm{P}<0.05)$

Fig. 6 The proliferation curves of human lung cancer H1299 and HCC817 cells. (A) The proliferation curve of H1299 cells. (B) The proliferation curve of HCC827 cells. The cells were treated 
1 with the aqueous extracts of 3-day-old radish sprouts which had been boiled or steamed or microwaved

2 for $0.5 \mathrm{~min}$ before used. The data were expressed as mean \pm standard deviation ( $\mathrm{n}=3$ ). Means with

3 different letters at each time point differed significantly $(\mathrm{P}<0.05)$

4 Table 1 Effects of cooking treatments on the myrosinase activity in radish sprouts

5 




2 Fig. 1 The formation and degradation of sulforaphene (SFE) and chromatograms of the analysis

3 HPLC of SFE in radish sprouts germinated for $0,3,7$ days

4 


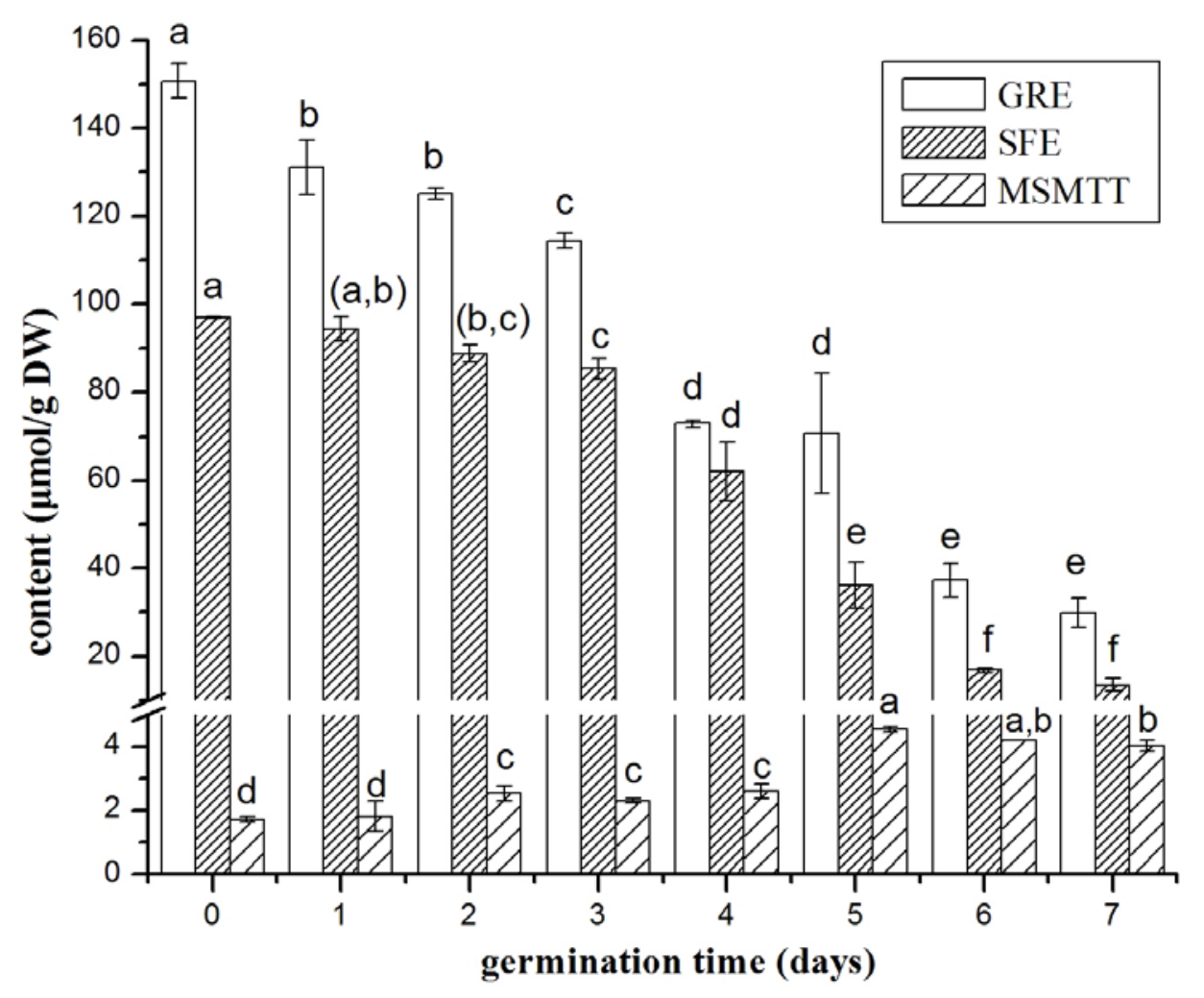

2 Fig. 2 Levels of glucoraphenin (GRE), sulforaphene (SFE) and its hydrolysis product (MSMTT) in

3 radish sprouts germinated for 0-7 days. The data were expressed as mean \pm standard deviation $(n=3)$.

4 Means with different letters reflect the significant difference in the levels of GRE, SFE and MSMTT

5 respectively $(\mathrm{P}<0.05)$

6 

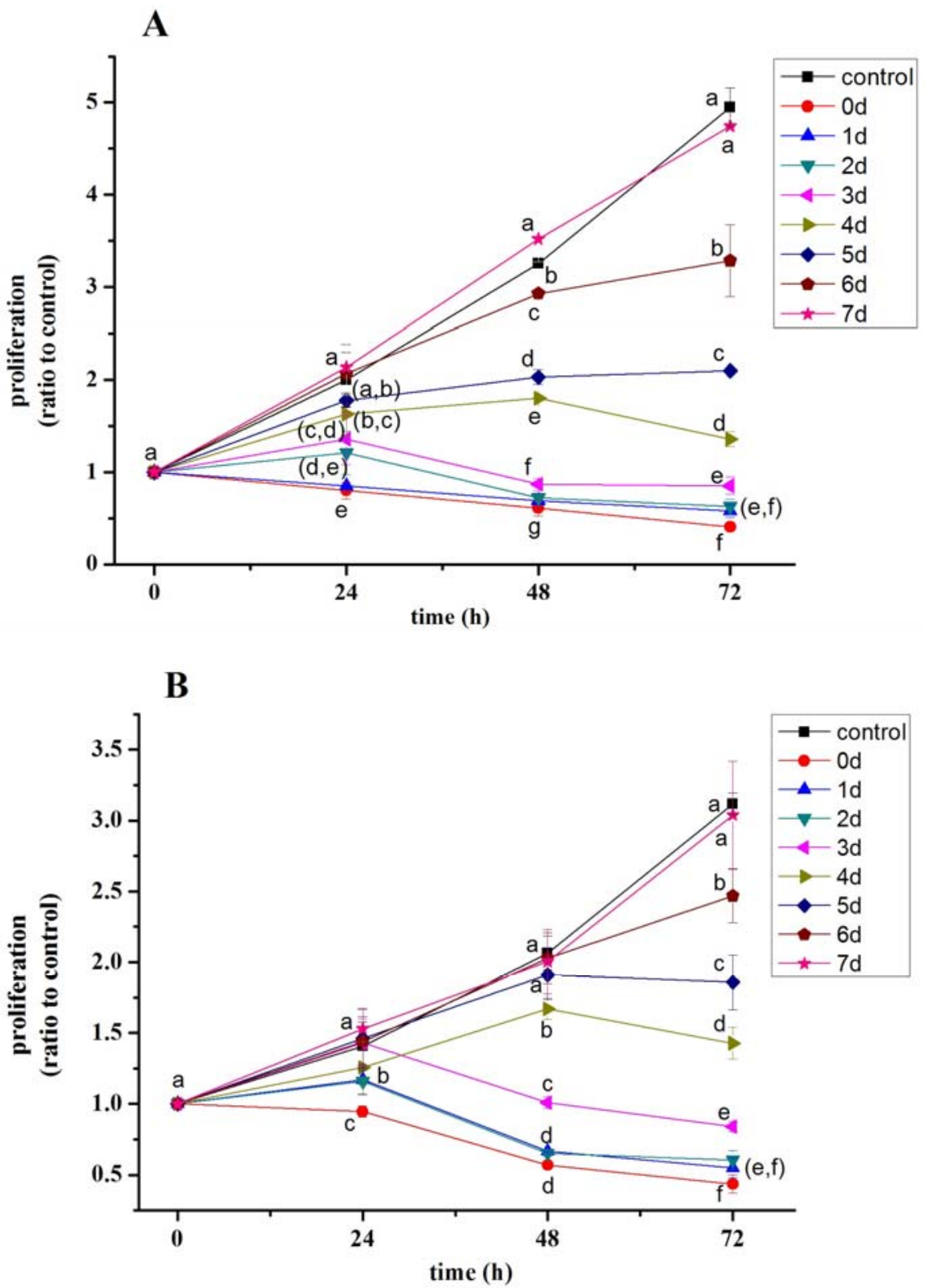

3 Fig. 3 Effects of aqueous extracts from radish sprouts on the proliferation of human lung cancer

$4 \mathrm{H} 1299$ (A) and HCC817 cells (B). The cells were treated with the aqueous extracts from radish sprouts

5 germinated for 0-7 days. The data were expressed as mean \pm standard deviation $(n=3)$. Means with

6 different letters at each time point differed significantly $(\mathrm{P}<0.05)$ 

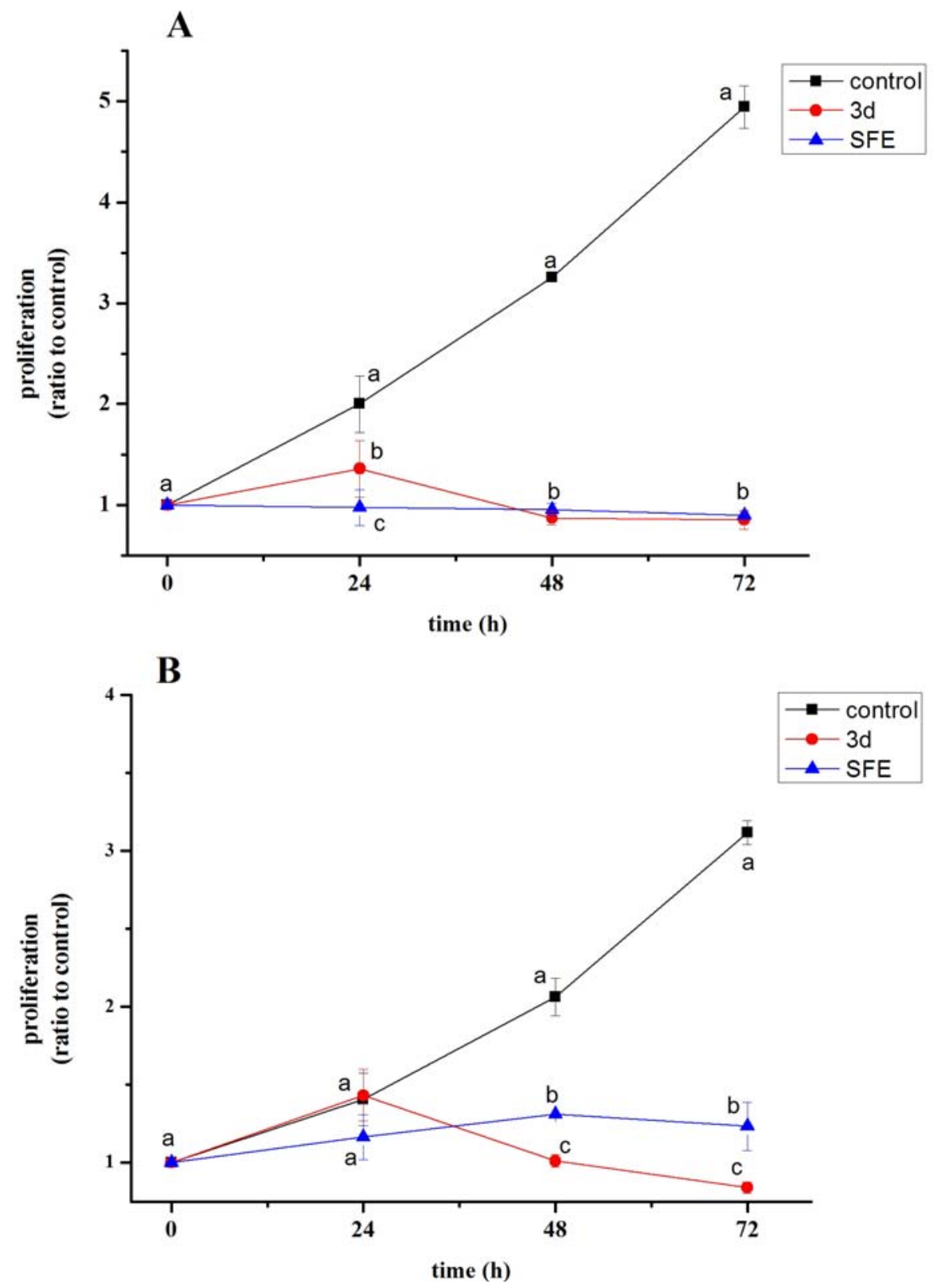

3 Fig. 4 The proliferation curves of human lung cancer H1299 (A) and HCC817 cells (B) exposed to

4 the aqueous extracts from 3-day-old radish sprouts or $20 \mu \mathrm{M}$ sulforaphene (SFE). The data were

5 expressed as mean \pm standard deviation $(\mathrm{n}=3)$. Means with different letters at each time point differed

6 significantly $(\mathrm{P}<0.05)$

7 
A



1

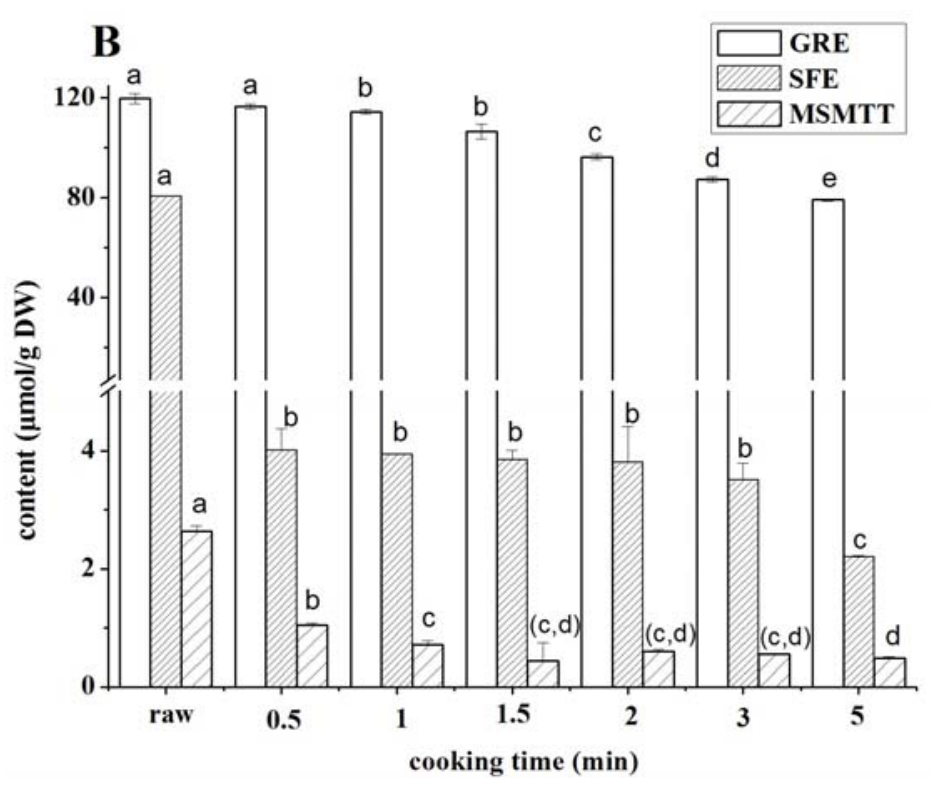

2

$$
\text { C }
$$




1 Fig. 5 Effects of three heat treatment methods on the levels of glucoraphenin (GRE), sulforaphene

2 (SFE) and its hydrolysis product (MSMTT) in radish sprouts. Three-day-old radish sprouts radish

3 sprouts were heated by boiling (A), steaming (B) and microwaving (C) for various time periods. The

4 data were expressed as mean \pm standard deviation $(n=3)$. Means with different letters reflect the

5 significant difference in the levels of GRE, SFE and MSMTT respectively $(\mathrm{P}<0.05)$ 
A

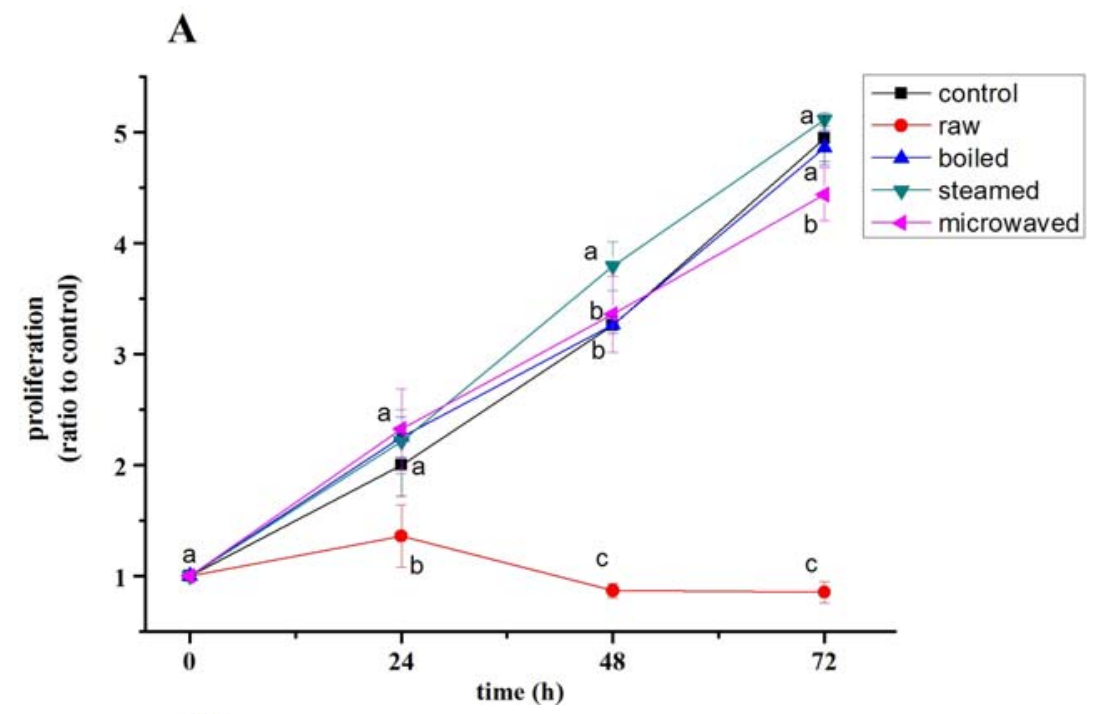

1

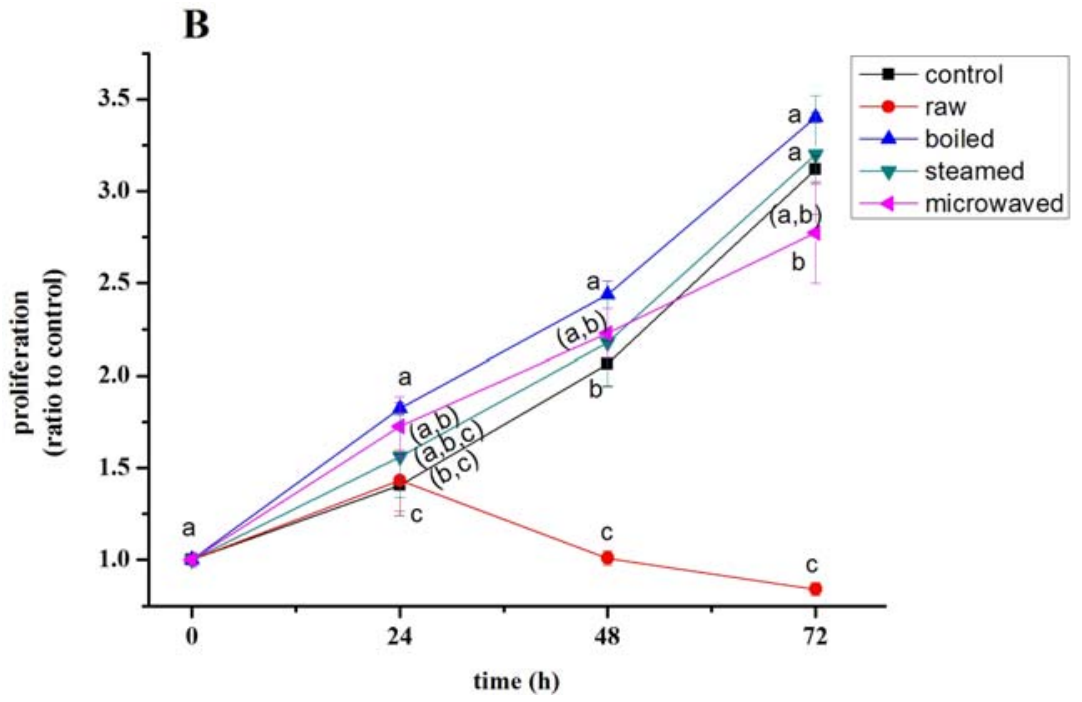

Fig. 6 The proliferation curves of human lung cancer H1299 and HCC817 cells. (A) The

4 proliferation curve of $\mathrm{H} 1299$ cells. (B) The proliferation curve of HCC 827 cells. The cells were treated

5 with the aqueous extracts of 3-day-old radish sprouts which had been boiled or steamed or microwaved

6 for 0.5 min before used. The data were expressed as mean \pm standard deviation $(n=3)$. Means with

7 different letters at each time point differed significantly $(\mathrm{P}<0.05)$

8 
1 Table 1 Effects of cooking treatments on the myrosinase activity in radish sprouts

\begin{tabular}{cc}
\hline Cooking treatment & $\begin{array}{c}\text { Myrosinase activity }^{\mathrm{a}} \\
\text { (units }^{\#} / \mathrm{mg} \text { protien) }\end{array}$ \\
\hline Raw & $1.81 \pm 0.006 \mathrm{a}$ \\
steaming & $0.21 \pm 0.02 \mathrm{~b}$ \\
microwaving & $0.09 \pm 0.005 \mathrm{c}$ \\
boiling & $0.08 \pm 0.003 \mathrm{c}$
\end{tabular}

2 a The data were expressed as mean \pm standard deviation $(n=3) .{ }^{*}$ One unit of enzyme activity is defined

3 as the amount of enzyme which catalyzes $1 \mu \mathrm{mol}$ sinigrin per minute at $37^{\circ} \mathrm{C}$. Means with different

4 letters in the same column differed significantly $(\mathrm{P}<0.05)$ 